\title{
Do Paper Circuit à programação de Arduino com Scratch: uma sequência didática para aprendizagem do conteúdo de energia nos anos iniciais do Ensino Fundamental
}

\author{
Elaine Silva Rocha Sobreira ${ }^{1}$, Alessandra Aparecida Viveiro ${ }^{2}$, João Vilhete Viegas \\ d'Abreu ${ }^{3}$ \\ ${ }^{1}$ Programa de Pós-Graduação Multiunidades em Ensino de Ciências e Matemática - \\ Universidade Estadual de Campinas, Unicamp - Campinas, São Paulo, Brasil
}

${ }^{2}$ Faculdade de Educação, Universidade Estadual de Campinas, Unicamp - Campinas, São Paulo, Brasil

${ }^{3}$ Núcleo de Informática Aplicada à Educação - NIED, Universidade Estadual de Campinas, Unicamp - Campinas, São Paulo, Brasil

elainesilvarocha@gmail.com; alessandraviveiro@gmail.com; jvilhete@unicamp.br Abstract. The present article describes a didactic sequence, developed in science
classes of the 5th grade of elementary school in a public school located in a city in
the Greater São Paulo, Brazil. The objective was to develop strategies so that
students could expand their knowledge on the subject of energy through the
installation and programming of electrical circuits using low cost or recycled
materials and also prototyping boards. The work had as its starting point the
construction of paper circuits following to build up circuits with sensors and
actuators using the Arduino board programmed for Scratch utilization and Makey
Makey shield as well, for power conduction studies.

Resumo. O presente artigo descreve uma sequência didática, desenvolvida nas aulas de ciências do $5^{\circ}$ ano do Ensino Fundamental, em uma escola pública de um município da Região Metropolitana de São Paulo, Brasil. Tem por objetivo relatar uma prática pedagógica desenvolvida em uma escola pública, que procurou contribuir para que os estudantes ampliassem seus conhecimentos em relação ao conteúdo de energia através da montagem e programação de circuitos elétricos utilizando materiais de baixo custo ou reaproveitados, além de placas de prototipagem. $O$ trabalho teve como ponto de partida a construção de circuitos de papel, seguindo para a construção de circuitos com sensores e atuadores utilizando a placa Arduino programada com Scratch, além da placa Makey Makey para estudos de condução de energia.

\section{Introdução e Justificativa}

A necessidade de um acesso mais amplo dos indivíduos à cultura científica justifica a defesa do ensino de Ciências nos diferentes níveis de escolarização, desde os anos iniciais. Para se 
desenvolver um aprendizado efetivo, faz-se necessário a superação de aulas meramente expositivas, pautadas na memorização, avançando para um trabalho que envolva práticas diversificadas, contemplando, por exemplo, a abordagem ciência-tecnologia-sociedade(ambiente) (CTS/CTSA), a experimentação em uma abordagem investigativa e a exploração das tecnologias digitais de informação e comunicação (TDIC) (Viveiro \& Zancul, 2014).

O potencial pedagógico das novas tecnologias, apesar de ser reconhecido, ainda carece de aprofundamento nas práticas pedagógicas. Almeida e Valente (2012) reforçam a necessidade de se desenvolver práticas de web currículos, em que as TDIC estejam imbricadas no desenvolvimento do currículo em atividades pedagógicas, de modo que estes recursos sejam utilizados no processo de aprendizagem, extrapolem as fronteiras da sala de aula, superando os currículos apresentados apenas nos livros e estabelecendo relações com as práticas cotidianas nos diversos espaços de saber que envolvem a sociedade. Nesta mesma linha, estes autores, em outro estudo, abordam a necessidade de se fazer a integração da tecnologia ao currículo com base nas facilidades oferecidas pela Web 2.0, num contexto no qual a convergência das trajetórias das tecnologias e do currículo é totalmente viável (Almeida \& Valente, 2011).

Essa relação das TDIC com o currículo pode se tornar muito significativa quando aliada à aprendizagem dos conteúdos de ciências, dentro de uma abordagem CTS/CTSA. A partir de diversos autores, Santos $(2007$, p. 2) afirma que um currículo organizado na perspectiva CTS tem como objetivo básico propiciar "a educação científica e tecnológica dos cidadãos, auxiliando o aluno a construir conhecimentos, habilidades e valores necessários para tomar decisões responsáveis sobre questões de ciência e tecnologia na sociedade e atuar na solução de tais questões".

O ensino de ciências deve trabalhar nesta perspectiva desde os anos iniciais, buscando a formação integral do indivíduo. Para tanto, alguns temas são bastante favoráveis. É o caso do tema energia, a partir do qual pode-se integrar as TDIC com o currículo de ciências, permitindo o desenvolvimento de uma aprendizagem prática, reflexiva e criativa, possibilitando a criação de espaços e recursos que propiciem um diálogo "sobre as questões energéticas, em diferentes perspectivas, conhecimentos e experiências" (Nishida et al., 2014, p. 668).

$\mathrm{Na}$ literatura científica, há alguns trabalhos interessantes que integram o uso das TDIC, incluindo placas de prototipagem, para o ensino e aprendizagem envolvendo os conteúdos relacionados à energia. Ramos e Andrade (2015), por exemplo, tiveram como objetivo o desenvolvimento de um instrumento eletrônico de baixo custo que fosse capaz de medir o consumo de energia elétrica e de água de forma simultânea, de forma a auxiliar o ensino de Engenharia por meio da construção de um objeto de ensino para replicação em oficinas. Já Leal e colaboradores (2015) desenvolveram um dispositivo robótico (protótipo) com objetivo de conseguir maior aproveitamento de energia solar capturada por placas fotovoltaicas. Machado e Queiroz (2015) trabalharam com alunos dos anos iniciais do Ensino Fundamental, desenvolvendo uma sequência de atividades. Partiram de uma experiência de condução de eletricidade utilizando uma batata doce para acionar uma calculadora e acender um LED. Em seguida, houve a construção de uma maquete controlada por Arduino, envolvendo fenômenos físicos e tecnológicos referentes à energia elétrica. $\mathrm{Na}$ última etapa, discutiram sobre atitudes que promovem a economia de energia elétrica e formas alternativas de produção. 
Tendo em vista esses pressupostos, este texto tem por objetivo relatar uma prática pedagógica desenvolvida em uma escola pública, que procurou contribuir para que os estudantes ampliassem seus conhecimentos em relação ao conteúdo de energia através da montagem e programação de circuitos elétricos utilizando materiais de baixo custo ou reaproveitados, além de placas de prototipagem. Todos os 22 alunos envolvidos no processo já tinham um contato prévio com o ambiente de programação Scratch através da criação de animações, porém não conheciam a possibilidade de integração com placas físicas como o Arduino e Makey Makey, sendo estes recursos totalmente desconhecidos pelos alunos, os quais tiveram o primeiro contato à partir deste trabalho. Destaca-se, aqui, a fase inicial do trabalho, voltada às primeiras aproximações com conceitos e práticas.

O trabalho se aproxima daquele desenvolvido por Machado e Queiroz (2015), as quais iniciaram com uma atividade concreta (condução de eletricidade por batata doce) e pela utilização de vídeos para enriquecer a discussão do tema, seguindo para a construção com Arduino. O diferencial do trabalho aqui relatado está na integração de recursos variados, com o intuito de abordar diferentes aspectos que envolvem o tema energia.

Este artigo foi organizado da seguinte forma: a seção 2 apresenta a criação de circuitos elétricos para compreensão do tema de energia abordando os "Paper Circuits", a placa Arduino com uso de sensores e atuadores, as placas Makey Makey e o Arduino programado com Scratch 2.0 offline. A seção 3 descreve a sequência didática e a seção 4 apresenta os resultados e discussões. Por fim, a seção 5 traz considerações e propostas para trabalhos futuros.

\section{Criação de circuitos elétricos para compreensão do conceito de energia}

Pensando no contexto de ensino de ciências para crianças, é importante trabalhar com vivências, propiciar situações para que coloquem a "mão-na-massa", favorecendo a construção de significados para os fenômenos observados. Nesse sentido, para a compreensão de como se dá a dinâmica de funcionamento de um circuito elétrico, buscou-se a utilização de materiais acessíveis e seguros para os alunos manipularem e que fornecessem uma diversidade de possibilidades.

Materiais como circuitos de papel e o uso de sensores e atuadores conectados na placa Arduino permitem vivenciar desde a ligação de um simples LED até a geração de energia por meio do uso de placas fotovoltaicas e motores com hélices de energia eólica. O Makey Makey, por sua vez, permite experiências criativas de condução de energia.

A seguir, descreve-se brevemente algumas possibilidades de uso destes materiais e a facilidade de programação do Arduino através do Scratch 2.0 offline, tendo em vista a importância da utilização das novas tecnologias digitais e da programação para "envolver o aluno em atividades participativas, que estimulem seu raciocínio, em consonância com uma prática formativa e não meramente armazenadora de informações" (Oro, Pazinato \& Gross, 2015, p.105).

\subsection{Criação de circuitos de papel}

Os circuitos de papel, ou "Paper Circuits", foram difundidos através do trabalho de Jie Qi em sua pesquisa de mestrado, cujo objetivo era apresentar circuitos eletrônicos de uma maneira acessível, facilitando a compreensão conceitual e tornando intuitivo o trabalho com 
componentes físicos. Ao situar estes conceitos como mídias criativas e expressivas, Jie buscou promover um espaço lúdico onde se pode aprender e fazer a eletrônica (Qi, 2012). Esses circuitos são possíveis através da utilização de simples componentes, como papel, LED, fita condutiva de cobre ou alumínio e uma bateria de 3 Volts. Para acender um LED, basta conectar a bateria ao LED através de um loop completo, combinando o lado positivo do LED com o lado positivo da bateria através da fita adesiva condutiva, que pode ser colada em uma folha de papel (o mesmo deve ser feito com o lado negativo). Isso permite com que o fluxo de eletricidade da bateria siga através da fita condutiva até o LED, fazendo com que a luz possa acender.

Pela facilidade de montagem, familiaridade dos alunos com a maior parte do material (papel sulfite, fita adesiva e baterias de relógios) e possibilidade fácil e prática de desmontar e refazer, possibilitando corrigir e reorganizar o circuito, optou-se por iniciar o trabalho com circuitos elétricos através desta proposta. Na Figura 1, é possível verificar a montagem de um circuito de papel, através da ligação da fita de cobre com o LED e a bateria, ao dobrar o papel a fita condutiva do lado positivo do LED fecha o circuito.

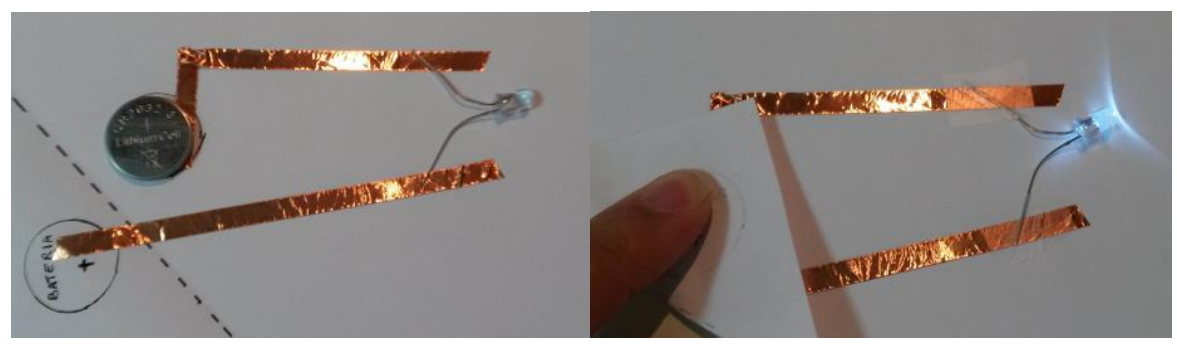

Figura 1. Montagem de um circuito com papel

De acordo com Qi (2012), a facilidade em se trabalhar com circuitos de papel vai além da familiaridade com o material necessário, contemplando também o baixo custo dos materiais utilizados, o que reduz a preocupação em quebrar ou desperdiçar materiais preciosos. Isso favorece a experimentação e retira a preocu pação em errar, que são vitais para a aprendizagem e pensamento criativo. Isto porque a fita de cobre pode ser facilmente cortada se uma conexão estiver incorreta, ou descolada se for colocada no local errado, incentivando os usuários a fazerem modificações, quando necessário, sem se preocupar com dano estético ou de material.

\subsection{Placa Arduino, sensores e atuadores}

O Arduino (Figura 2 - Esquerda) é uma plataforma Open Source de prototipagem eletrônica. Foi desenvolvido em 2005 no Ivrea Interaction Design Institute, na Italia, por Massimo Banzi e sua equipe, que tinha por objetivo criar uma ferramenta fácil para prototipagem rápida, destinado a estudantes sem experiência em eletrônica e programação (https://www.arduino.cc/). As placas Arduinos são capazes de ler entradas (como a luz de um sensor, o acionamento de um botão ou uma mensagem de Twitter) e transformá-lo em uma saída (ativar um motor, ligar um LED, publicar algo online).

Seu ambiente de programação é o software Prossessing, baseado na linguagem C, porém também permite ser programado pelo Scratch 2.0 offline, através da configuração e instalação de alguns programas, sendo eles a IDE do Arduino, Python, PySerial e PyMata. Existe um pacote com instalador direto, sendo possível encontrar o arquivo e o tutorial de instalação no site Hackeduca, através do link: http://bit.ly/2bbEOC9. 
Dentre os sensores e atuadores do Arduino, alguns deles podem facilitar o desenvolvimento do trabalho envolvendo conceitos de energia com estudantes dos anos iniciais. Por exemplo, pode-se trabalhar com a construção de circuitos que envolvem a ligação de polos positivos e negativos, acendendo LEDs, fazendo a leitura de sensores e ligando dispositivos através de placas de energia solar ou funcionamento de motores, permitindo que os alunos possam manipular e visualizar em tempo real as ligações e reações decorrentes através da ligação dos circuitos.

\subsection{Placa Makey Makey para condução de energia}

O Makey Makey (Figura 2 - Direita) é uma placa de circuito impresso com um microcontrolador Arduino ATMEGA32U4, que funciona substituindo as funções do mouse e/ou do teclado, através de conexões com fios de "garra jacaré". Seu poder inovador está na característica de conexão com materiais pouco condutivos como, por exemplo, massa de modelar, pessoas, líquidos ou até mesmo frutas e legumes. Essas conexões podem virar uma extensão criativa do computador, favorecendo a interação, pois utiliza o protocolo de dispositivo de interface humana (HID) para se comunicar com o computador, permitindo enviar sinais das teclas pressionadas, cliques e movimentos do mouse (Silver \& Rosenbaum, 2016). Dispensa qualquer conhecimento prévio sobre programação ou eletrônica, basta conectar os cabos e utilizar em qualquer programa de computador, desde um simples editor de texto, páginas da Web ou até mesmo ambientes de programação como o Scratch.
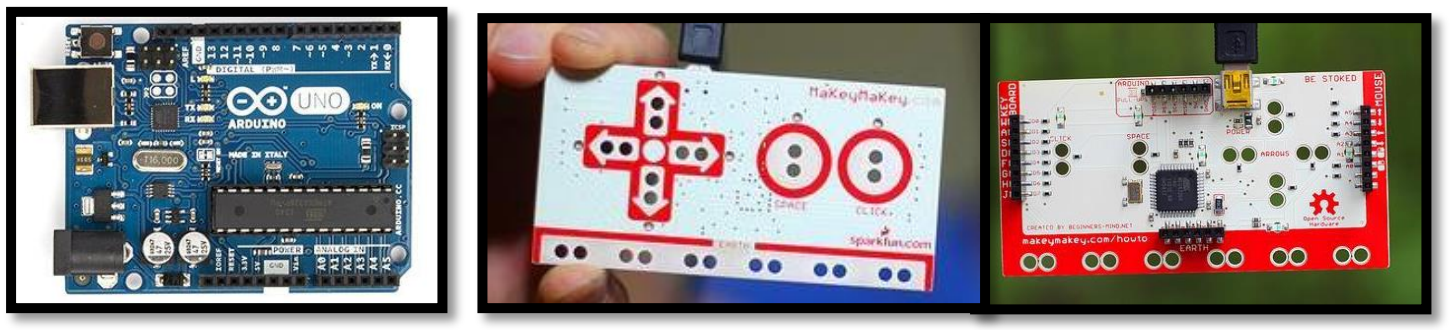

Figura 2. Esquerda: Placa Arduino Uno. Disponível em: https://www.arduino.cc/en/Guide/MacOSX. Direita: Placa Makey Makey frente e verso. Disponível em: http://www.makeymakey.com/

\subsection{Programação do Arduino através do Scratch 2.0 offline}

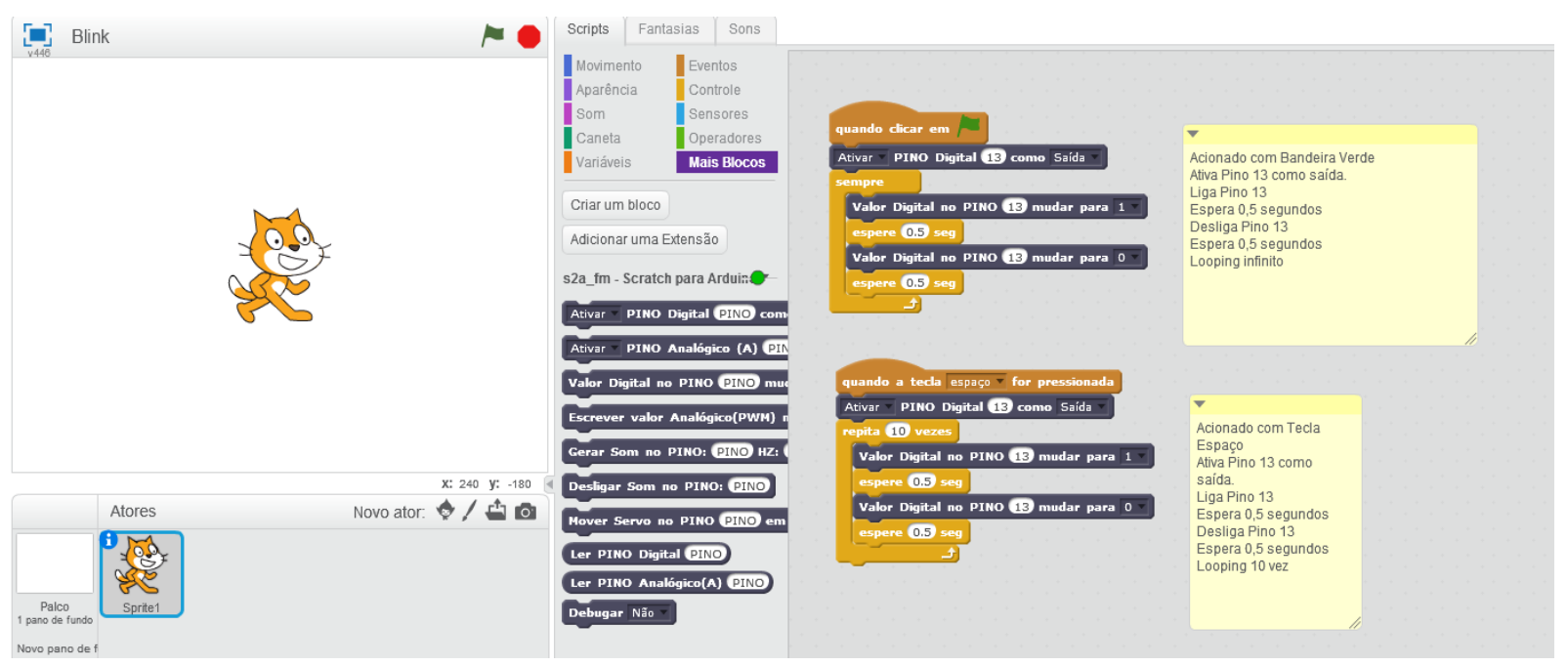

Figura 3. Blocos disponíveis para programação do Arduino no Scratch 2.0 offline 
V Congresso Brasileiro de Informática na Educação (CBIE 2016)

Anais do XXII Workshop de Informática na Escola (WIE 2016)

Com a instalação dos programas citados, é possível programar o Arduino através do Scratch 2.0. O diferencial é a inserção de comandos na aba "Mais blocos", conforme demonstrado na Figura 3. O Arduino programado com Scratch pode ser utilizado para auxiliar o aluno no processo de aprendizagem, tornando a tecnologia um instrumento do seu desenvolvimento pessoal (Bastos, Borges \& D’Abreu, 2010).

\section{Desenvolvimento da sequência didática}

O trabalho foi desenvolvido no contexto de uma pesquisa de intervenção, com abordagem qualitativa, em que a pesquisadora teve uma participação ativa, atuando como pesquisadoraparticipante. Foi desenvolvido em uma escola pública municipal, localizada na Grande São Paulo, Brasil, com uma turma de 22 alunos do $5^{\circ}$ ano do Ensino Fundamental. A turma tem redução de número total de alunos por ser uma classe de inclusão, com uma aluna surda que faz leitura labial.

O conteúdo energia foi escolhido de acordo com o currículo de ciências que seria abordado no trimestre. Apesar dos alunos já conviverem com diferentes tipos de energia e terem contato com este termo na mídia, que frequentemente trata de temas como apagões, crise das usinas hidrelétricas, aumento dos preços dos combustíveis, dentre outros, o seu conceito é abstrato e difícil de compreender apenas através de recursos teóricos. Com o intuito de concretizar os conhecimentos teóricos e contextualizá-los no cotidiano dos alunos através de experiências práticas, esta sequência didática foi desenvolvida.

O objetivo principal foi que os alunos fossem capazes de identificar algumas fontes de energia e entender a sua aplicação na vida cotidiana em diferentes ambientes. Os objetivos específicos envolveram: compreender como as diferentes fontes de energia são utilizadas no nosso cotidiano; conhecer os elementos de um circuito elétrico; identificar diferentes fontes de energia; entender como ocorre a transformação de um tipo de energia para outro.

Como uma forma de diagnosticar os conhecimentos prévios dos alunos, em grupo, eles levantaram hipóteses para responder as seguintes questões: Para que precisamos de energia? De onde vem a energia? Após a avaliação diagnóstica e discussão dos saberes dos alunos, foram realizadas as seguintes etapas práticas:

1- Construção de um circuito de papel para acender um LED utilizando os seguintes materiais: bateria de $3 \mathrm{~V}$, fita adesiva de core, papel sulfite e LED. Foi retomada a conversa da aula anterior sobre circuitos elétricos, verificando como a energia chega até os eletrodomésticos. A aula iniciou-se com o vídeo: "A eletricidade e a lâmpada elétrica", disponível em: http://youtu.be/pqpVONj4wmY e discussão. Os estudantes receberam orientação sobre como fazer a identificação dos polos positivos e negativos do LED e da bateria e desafiados a utilizar as fitas adesivas como fios condutores de energia, para formar um circuito completo.

2- Utilização do jogo de simulação PhET Kit de construção de circuito DC (Figura 4), para ligação de circuitos, disponível em: http://bit.ly/2baQPur.

3- Apresentação da placa Arduino e os comandos de programação disponíveis no Scratch. Proposta de montagem de circuito com LED e LDR através das portas do Arduíno de 5v, Gnd e porta digital para acender um LED e a função das portas digitais para acender um sensor LDR. Foram oferecidas fichas do Scratch (Figura 5) preparadas como um tutorial para 
V Congresso Brasileiro de Informática na Educação (CBIE 2016)

Anais do XXII Workshop de Informática na Escola (WIE 2016)

acender o LED e outro sobre o acionamento do LDR e proposto um desafio no Scratch para criar uma programação com uma condicional para acender o LED através da leitura do LDR.

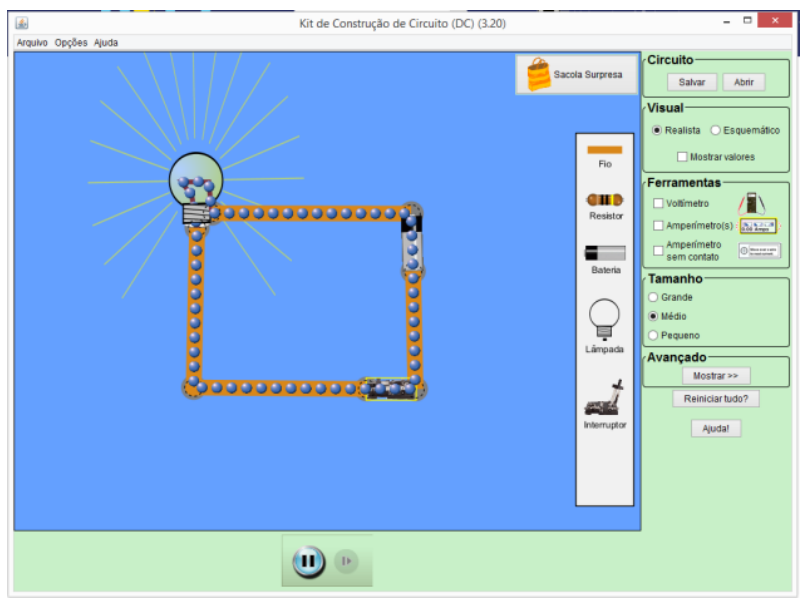

Figura 4. Simulação de um circuito simples

4- Utilização de um motor com hélice para geração de energia eólica com o intuito de acionar movimentos no Scratch. A aula iniciou com uma discussão do vídeo Energia Eólica, do Jornal Nacional exibido em 09/06/2012, disponível em: http://youtu.be/XsuxJM6cX2s. Em seguida, os estudantes receberam novas fichas do Scratch para fazer a ligação do motor, e a proposta de criação de um desafio no Scratch para criar ações decorrentes do acionamento da turbina de energia eólica.

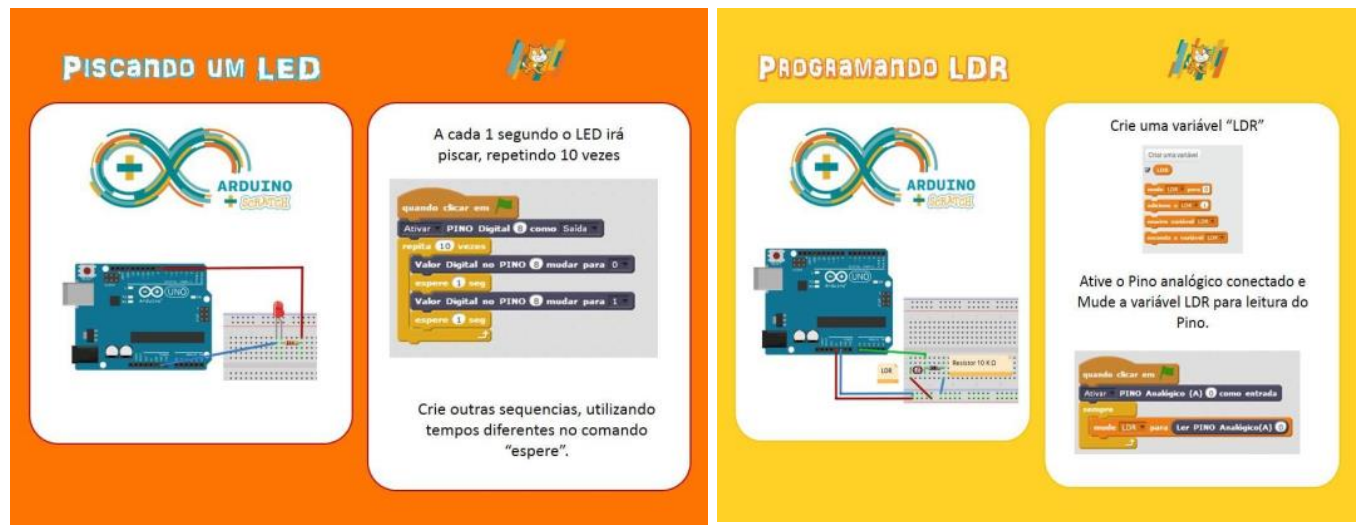

Figura 5. Fichas do Scratch confeccionadas como tutorial para conexão do LED e LDR no Arduino e programação no Scratch 2.0 offline

5- Utilização de mini placas de energia solar (material reaproveitado de luminárias de jardim). A aula foi iniciada com uma discussão do vídeo Espelhos e Robôs geram energia solar exibido no Jornal da Globo em 2010, disponível em: http://youtu.be/WDQdhBVZd6o. Em seguida, foi oferecido aos alunos fichas Scratch para acionar atuadores através da placa e propor um desafio para relacionar a ligação realizada com alguma animação no Scratch.

6- Utilização das placas Makey Makey para discussão da condução de eletricidade. A aula iniciou com o vídeo "Mad Science - Eletricidade e condutores", disponível em: http://bit.ly/2aPZZLS. Foi explicado para os estudantes as ligações do Makey Makey e eles receberam materiais condutores e não condutores (massa de modelar, copo com água, clipes de metal, palitos de madeira, tampinhas de garrafas PET, argolinhas de alumínio, bananas e 
carretéis de plástico) para testar qual deles fecharia o circuito. Foram desafiados a criar uma animação no Scratch que funcionasse através dos comandos dos materiais condutores.

\section{Resultados e discussões}

$\mathrm{Na}$ avaliação diagnóstica foi detectado que os alunos tinham uma variedade de respostas para o uso da energia, sinalizando o uso para: conservar alimentos, iluminar a cidade, funcionar o comércio, sacar dinheiro, evitar acidentes de transito (semáforos funcionando) e ligar eletrodomésticos. No entanto, desconheciam as diversas fontes de energia, quase todos alunos responderam que a energia vem da água, uma aluna disse que vem da "usina elétrica", um aluno disse que vem do poste de luz e outro que vem da tomada. Apenas uma aluna respondeu que a energia também pode vir do sol. Em relação a transformação de energia, a maioria dos alunos respondeu que não, apenas um aluno disse que "sim, se a energia se transformar novamente em água sim" e a aluna que falou da energia do sol disse que "a energia solar pode transformar em elétrica". Isto demonstrou o desconhecimento das fontes alternativas de energia, de sua possibilidade de transformação e, até mesmo, de onde vem a energia que utilizam.

Para que pudessem partir da noção de onde vem a energia que utilizam, antes de conhecer outras fontes, assistiram a vídeos e participaram de discussões à respeito da produção de energia em usinas hidrelétricas, discutindo também como a energia percorre o caminho até as residências chegando, enfim, na tomada.

Quando os estudantes foram desafiados a construir o circuito de papel, eles tentaram utilizar a fita adesiva como fio condutor, mas não conseguiram perceber o modo de fazer a conexão da bateria nos dois polos. Sendo assim, todos os grupos ligaram o LED direto na bateria e utilizaram a fita de cobre como simples adesivo para fixar o material no papel (Figura 6, esquerda). Foi discutida a primeira ligação em uma roda de conversa e, com exemplos reais de como a ligação de uma lâmpada é feita, eles perceberam a necessidade de ligar o LED através do fio.
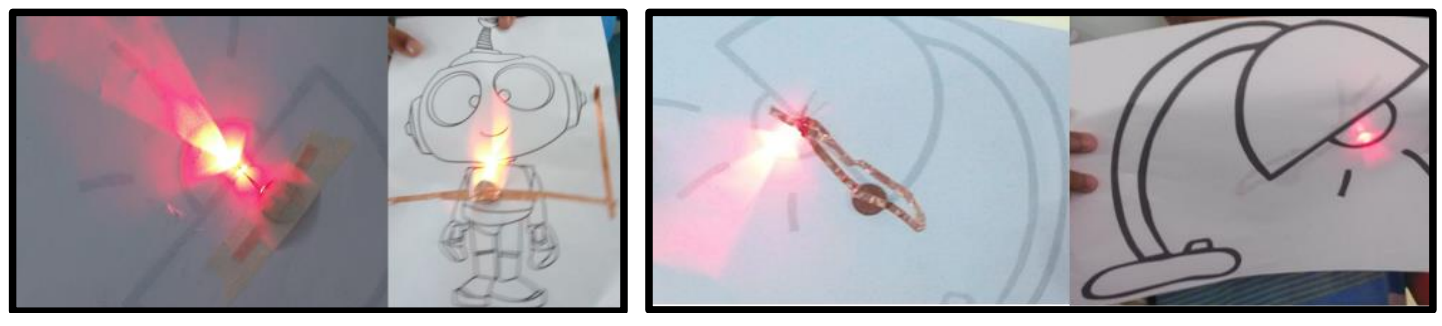

Figura 6. Esquerda: utilização da fita condutiva apenas como adesivo. Direita: ligação da fita como condutora dos polos positivos e negativos.

Desta forma, retomaram a atividade e discutiram nos grupos formas de realizar a ligação. O grupo 1 discutia que, se o lado da "perna maior" do LED era positivo, precisava colocar uma fita condutiva também maior para ligar no polo positivo e grudaram a fita adesiva no polo positivo e tentaram dobrar a outra conexão (negativa) em cima da folha, conectando $2 \mathrm{x}$ no lado positivo da bateria, precisaram de intervenção para entender como colocar a fita dos dois lados da bateria. Um aluno do grupo 2 chegou à conclu são que deveria colocar o fio negativo do lado de baixo da bateria e o fio positivo do lado de cima que tinha o sinal de "+", desta forma, conseguiram estabelecer a ligação (Figura 6, direita). Os estudantes dos primeiros grupos que conseguiram foram ajudando os demais. 
No jogo PhET de simulação para ligação de circuitos, após a montagem de circuitos simples, os alunos testaram diversas associações de montagens, acrescentaram outras quantidades de lâmpadas, baterias, etc. Alguns alunos descobriram que ligações erradas não apenas deixavam de funcionar, mas também era possível causar curto-circuito e disseram "Nosso jogo pegou fogo!".

Na primeira aula de Arduino, o aluno 1 comentou: "Por que as pessoas complicam nossa vida, estava tão fácil fazer o circuito com a fita no papel?", a professora interviu e questionou se não havia nenhuma mudança de possibilidades do Arduino com o circuito de papel e, após o aluno observar a programação, ele chegou à conclusão que no papel apenas acendia e não era possível programar, já no Arduino ele poderia decidir se o LED iria piscar com frequência diferenciada, além de ter o sensor para fazer a leitura da luz. Conseguiu diferenciar a relação entre circuitos programados e não programados.

A aluna 2 escreveu em seu relato da aula: "aprendi como ligar fios na prática, muito mais sobre o lado positivo e o negativo, e também sobre o vídeo que a professora passou para agente assistir me ajudou bastante eu não sabia que a energia vinha da água".

No decorrer das aulas, os conhecimentos dos alunos sobre energia foram sendo ampliados gradativamente. Começaram a utilizar o nome correto dos tipos de energia (elétrica, luminosa, térmica, química, sonora, cinética e mecânica), além dos sensores, placas e os diversos materiais utilizados nas aulas.

$\mathrm{Na}$ aula de condução de energia do Makey Makey, primeiramente os alunos responderam uma ficha com alternativa colocando as hipóteses prévias sobre qual material poderia conduzir energia, depois realizaram as experiências e comprovaram se suas hipóteses iniciais eram verdadeiras ou falsas. A surpresa maior deles foi descobrir que pessoas e bananas podem conduzir eletricidade, pois na concepção deles apenas o que tinha metal poderia conduzir eletricidade.

\section{Considerações e trabalhos futuros}

Nessa sequência de aulas, os estudantes tiveram contato com diversos materiais e experimentaram na prática a ligação de circuitos, a geração, condução e transformação de energia, além de conhecer as fontes alternativas, ampliando seus conhecimentos em relação ao tema. Também foram capazes de relacionar com o cotidiano e perceber a utilidade prática de cada conceito, desenvolvendo assim, conceitos do trabalho relacionado a CTSA.

Iniciar o trabalho com circuitos de papel facilitou a compreensão do aluno, não apenas pelo fato de ser um material acessível, mas, inclusive, pelo fato de, nesta proposta, todas as ligações estarem visíveis, facilitando a compreensão das ligações da Protoboard (placa com furos e conexões condutoras para montagem de protótipos de circuitos elétricos) utilizada para conexão com Arduino. Isso reforça a possibilidade de utilizar materiais mais complexos com alunos dos anos iniciais, desde que eles sejam iniciados com propostas mais simples em processo gradativo de aprendizagem dos conceitos. Além disso, a utilização de ambientes de programação acessíveis como o Scratch que garantiu a autonomia dos alunos durante o processo.

Como continuidade do trabalho, os estudantes irão finalizar os estudos desenvolvendo um projeto de criação de jogos no Scratch com interação com as interfaces 
V Congresso Brasileiro de Informática na Educação (CBIE 2016)

Anais do XXII Workshop de Informática na Escola (WIE 2016)

físicas, utilizando os conhecimentos adquiridos em relação ao uso dos circuitos de papel, Arduino e Makey Makey.

\section{Referências}

Almeida, M. E. B. de e Valente, J. A. (2011) Tecnologias e currículo: Trajetórias convergentes ou divergentes? 1. ed. Editora Paulus, São Paulo.

Almeida, M. E. B. de e Valente, J. A. (2012) Integração currículo e tecnologias e a produção de narrativas digitais. Currículo sem Fronteiras, v. 12, n. 3, p. 57-82.

Bastos, B. L., Borges, M. e D’Abreu, J. (2010) Scratch, Arduino e o Construcionismo: ferramentas para a educação. Anais do Seminário de Tecnologia Educacional de Araucária "Desafios e Possibilidades para Tecnologia Educacional". Disponível em: <http://www. ft.unicamp.br/liag/robotica/downloads/a12.pdf>. Acesso em 26 de maio de 2016.

Machado, P. M. S E Queiroz, J. R. de O. (2015) Ensino de ciências nos anos iniciais: despertando competências conceituais e atitudinais. Anais do X Encontro Nacional de Pesquisa em Educação em Ciências - X ENPEC.

Nishida, A. K., Braga, J. C., Monteforte, A. e Benassi, R. F. (2014) Jogo educacional sobre consumo de energia elétrica. Anais do SBIE. Disponível em: <http://www.brie.org/pub/index.php/sbie/article/view/2997/2508>. Acesso em 28 de maio de 2016.

Oro, N. T., Pazinato, A. M., Teixeira, A. C. e Gross, A. J. (2015) A Olimpíada de Programação de Computadores para estudantes do ensino fundamental: a interdisciplinaridade por meio do software Scratch. Anais do WIE. Disponível em: <http://www.br-ie.org/pub/index.php/wie/article/view/5000/3410>. Acesso em 26 de maio de 2016

Qi, J. (2012) The Fine Art of Electronics: Paper-based Circuits for Creative Expression. Submitted to the Program in Media Arts and Sciences, School of Architecture and Planning in partial fulfillment of the requirements for the degree of Master of Science in Media Arts and Sciences at the Massachusetts Institute of Technology.

Ramos, M. C. e Andrade, V. S. (2015) Desenvolvimento, construção e calibração de uma central de monitoramento de consumo de energia elétrica e de água utilizando o microcontrolador Arduino. Anais do ENEDS.

Ramos, R. L., Castro, L. F. O., Bertagnolli, S. C. e Hübler, P. N. (2015) Uso da plataforma Arduino para criar um dispositivo robótico otimizando o aproveitamento de energia solar. Anais do Computer on the Beach.

Santos, W. L. P. (2008) Contextualização no ensino de ciências por meio de temas CTS em uma perspectiva crítica. Ciência \& Ensino.

Silver, J. e Rosenbaum, E. (2016) MaKey MaKey. An Invention Kit for Everyone. MIT Media Lab's Lifelong Kindergarten. Disponível em: <http://web.media.mit.edu/ ericr/makeymakey/>. Acesso em 25 de maio de 2016

Viveiro, A. A. e Zancul, M. C. S. (2014) Perspectivas para a formação de professores dos anos iniciais da escolarização em relação aos conteúdos de ciências. In: Jackson Gois (Org.). Metodologias e processos formativos em ciências e matemática. 1. ed. São Paulo: Paco Editorial, p. 9-26 